\title{
Chemical and Morphological Study of PM10 Analysed by SEM-EDS
}

\author{
Roberto Ramirez-Leal1 ${ }^{*}$, Maryanna Valle-Martinez², Martin Cruz-Campas ${ }^{1}$ \\ ${ }^{1}$ Environmental Industrial Engineering Program, Sonora State University, Hermosillo, Mexico \\ ${ }^{2}$ Ecology School, Sonora State University, Hermosillo, Mexico \\ Email: ramzl036@yahoo.com.mx
}

Received 30 September 2014; revised 30 October 2014; accepted 12 November 2014

Copyright (C) 2014 by authors and Scientific Research Publishing Inc.

This work is licensed under the Creative Commons Attribution International License (CC BY). http://creativecommons.org/licenses/by/4.0/

(c) $\underset{\mathrm{EY}}{\mathrm{B}}$ Open Access

\section{Abstract}

Single particle characterization can provide information on the evolution of size distribution and chemical composition of pollution aerosol. The work described the use of Scanning Electron Microscopy (SEM) combined with X-ray Dispersive Energy Spectrometry (EDS) to characterize inorganic atmospheric particles samples collected on PM10 filters from January 2013 to October 2013 from three zones within the city of Hermosillo, Sonora. Specimens were initially processed by separating the collected particles from the filters by means of submersing a $2 \mathrm{~cm}^{2}$ section of each filter into isopropilic alcohol within a test tube for 5 minutes. Then, an aliquot of the suspension was placed over a sample holder and into the SEM. The different elements found amongst individual particles were $\mathrm{Al}, \mathrm{Ba}, \mathrm{Ca}, \mathrm{Cl}, \mathrm{Cr}, \mathrm{Cu}, \mathrm{Fe}, \mathrm{K}, \mathrm{Mg}, \mathrm{Mn}, \mathrm{Na}, \mathrm{Pb}, \mathrm{S}, \mathrm{Si}$, Ti and $\mathrm{U}$. The predominant elements are Al (17.10 At\%), Si (10.17 At\%), Ba (5.90 At\%), Fe (5.45 At\%) and U (2.32 At\%). The particles were classified into groups based on morphology and elemental composition: particles of aluminosilicate, salts of sodium chloride, sulfates, metal particles, barium and uranium. These particles morphology and chemical composition, illustrate an abundance of natural elements within the zone. However, some of the elements presented are directly related with human activities, and are of much interest from the public health and environmental perspectives.

\section{Keywords}

PM10, Air Quality, SEM, EDS, Morphology

\section{Introduction}

The particulate air pollution is a growing problem in cities with emissions generating activities; these activities

${ }^{*}$ Corresponding author. 
are mainly industrial and vehicular widely developed in large cities in different countries. Particulate also called aerosols air pollution is caused due to very small liquid and solid particles suspended in the air. They originate from a variety of stationary and mobile sources and may be directly emitted (primary emission) or formed in the atmosphere (secondary emission) by transformation of gaseous emissions [1] [2].

The use of Scanning Electron Microscope (SEM) has found application in the field of particulate air pollution for several years, its use has helped the study of particle morphology and single particles chemical composition. In fact, the simultaneous characterization of both physical-chemical and morphological parameters of a complex mixture of organic and inorganic particulate matter is one of the major aspects for the characterization and identification of emission sources that contribute to particulate concentrations in the atmosphere [2].

Size and chemical composition of ambient particulates strongly influence on human health, visibility and ecosystem etc. thus it is crucial to investigate the physicochemical characteristics of atmospheric particles and also to evaluate their potential toxicity. A large number of health-related studies recognized that fine particles particularly submicron sizes, penetrate deep into lung and exacerbate chronic respiratory and pulmonary diseases [3] [4]. Such diseases also induce morphological and functional alterations in human pulmonary epithelial cells [5]. Apart from this, elemental composition of particulate plays an important role in the chemical characteristics of particulate matters (PM) and provides interesting data, not only for the evaluation of its impact on human health [6] [7], ecology and environment [7] [8] but also for the identification of specific emission sources [9] [10].

The size of particles and their concentrations are the basic characteristics of the atmospheric aerosols, allowing us to classify them, by its multimodal nature, in coarse particles, which have sizes larger than 10 microns, in fine particles, with sizes smaller than 10 microns and larger than 1 micron, and ultrafine particles, that have diameters smaller than 0.1 microns; all of these can be emitted so much by natural sources as by anthropogenic sources [2]-[11].

The size of the particles is then the characteristic most studied in terms of classification and health damage. However, if other features such as the chemical composition of the particle are considered the risk of health damage would probably be higher [12] [13].

Particulate matter with aerodynamic diameters less than $10 \mu \mathrm{m}$ (PM10) has been found to cause health problems. It can trigger or exacerbate conditions, such as asthma, emphysema, bronchitis, silicosis and lung cancer [13] [14]. PM10 has also been related to problems such as reduced visibility and unpleasant odour.

The chemical composition of inhalable particulate matter (PM10) suspended in the atmosphere is geographically variable and dependent on the type of local activity [14]. A typical mixture of PM contains sulfates (ammonium and calcium), nitrates (mainly ammonium), chlorides (mainly sodium), organic and elemental carbon (particularly related to vehicular traffic), biological materials and other organic compounds, iron compounds, trace metals and minerals derived from rocks, soil and construction, among other organic and inorganic compounds [14]-[16].

In this context, it is of fundamental importance to understand the origin, i.e. natural of anthropogenic, of the particles in the atmosphere. Previous studies on aerosols have been focused on their classification based on size, concentration and on chemical composition of whole particle masses; with relatively few details on the size, shape and chemical composition of their individual components [8]-[17].

Characterization of aerosol samples at the level of individual particles, using micro-analytical techniques, generally permits to obtain more unambiguous and detailed information than bulk analysis, and so it simplifies recognition of the sources of pollution and their processes [18] [19].

As the development of tools for more precise characterization of atmospheric aerosols has been steady, as is the case for the use of electron microscope as the impact it has had the use of electrons, the study of particles, has been enormous, since it has allowed to obtain a vast information on the nature, origin and chemical composition of our object of investigation [8] [10] [18].

Because the scanning electron microscope has sufficient specificity for the analysis of small particles and below the range of nanometers, we provide the information that was essential for observation of aerosols, since we can identify and fully characterize and individually, what is in our interest, from among a large group of particles [1] [2] [18].

Scanning microscope combines a brilliant image of the particle morphology, i.e. shape, size, roughness, etc. as well as analytical information of the chemical elements that comprise the analysis of single atmospheric particles by Scanning Electron Microscopy coupled with Energy Dispersive X-ray (SEM-EDS) is a powerful tool 
of recognizance emissions in urban places because the SEM may examine particles which are too small to be studied in the conventional optical microscope and also inform on the nature and origin of the particles revealed after the morphology, size and chemical composition [8]-[16].

These characteristics are important because they have influence on a particle's dwell time within the atmosphere and on its physical and chemical properties; these properties also have influence on global climate, the environment and on people's health.

The aim of this work is identification and characterization (morphology and chemical composition) of particles present in samples of PM10 as part of an air quality study by SEM-EDS.

\section{Materials and Method}

\subsection{Study Area}

Figure 1 indicates that the City of Hermosillo is located between latitude $20^{\circ} 01^{\prime} 00^{\prime \prime}$ and $20^{\circ} 08^{\prime} 30^{\prime \prime}$ north latitude and between the meridian $110^{\circ} 54^{\prime} 30^{\prime \prime}$ and $111^{\circ} 01^{\prime} 00^{\prime \prime}$ west longitude at an altitude of $200 \mathrm{~m}$ above sea level; is the state's capital, located to the center-west of the coastal plain, in the northwest region of Mexico.

The annual average temperature in the city of Hermosillo is $\pm 25^{\circ} \mathrm{C}$; with an annual precipitation of $315 \mathrm{~mm}$. This agrees to a dry-warm climate classification with extreme thermal oscillation, mostly of $\pm 14^{\circ} \mathrm{C}$. Precipitation is mainly restricted to a summer rain regime. During July, August and September, there is a season of strong winds whose velocities range between 60 to $80 \mathrm{~km} / \mathrm{h}$ and average relative humidity is $55 \%$; while on the rest of the year, mostly weak and dry winds occur. However, there are approximately 129 days of wind calm per year.

In this investigation, high volume samplers were used to collect PM10 from three atmospheric monitoring stations property of the Air Quality Improvement Municipal Program for the City of Hermosillo. The map shown in Figure 2 shows these locations. The first station is located in the northwestern area of the city, the second station in the downtown area, and the last station in the northeast area.

Table 1 describes the characteristics each zone; the northeastern station is surrounded by residential and roadside areas; the downtown station, by office commercial buildings and by high traffic areas, and finally, the northwestern station is also surrounded by high traffic zones and commercial buildings plus areas of industrial activity.

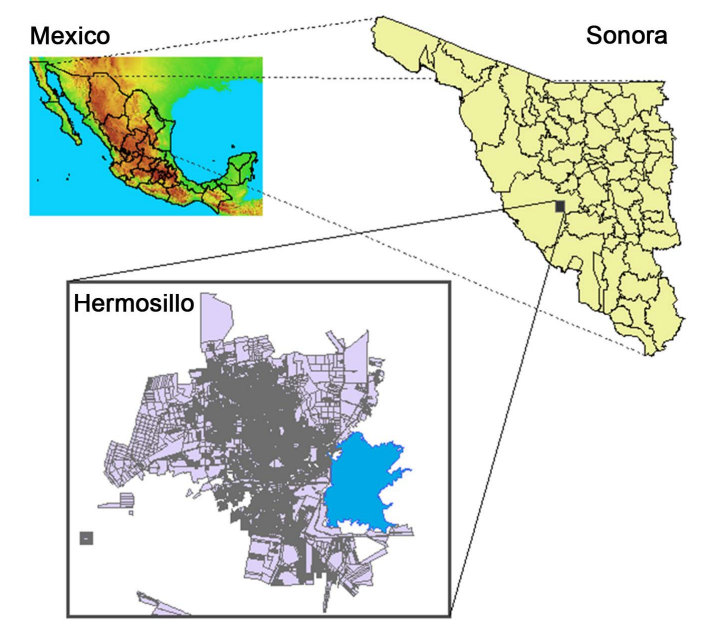

Figure 1. Geographic location.

Table 1. Atmospheric monitoring stations.

\begin{tabular}{cc}
\hline Area of the city & Characteristics of the zone \\
\hline Northeast (1) & Residential and roadside \\
Downtown (2) & Office commercial buildings and by high traffic \\
Northwestern (3) & High traffic zones and commercial buildings plus areas of industrial activity \\
\hline
\end{tabular}




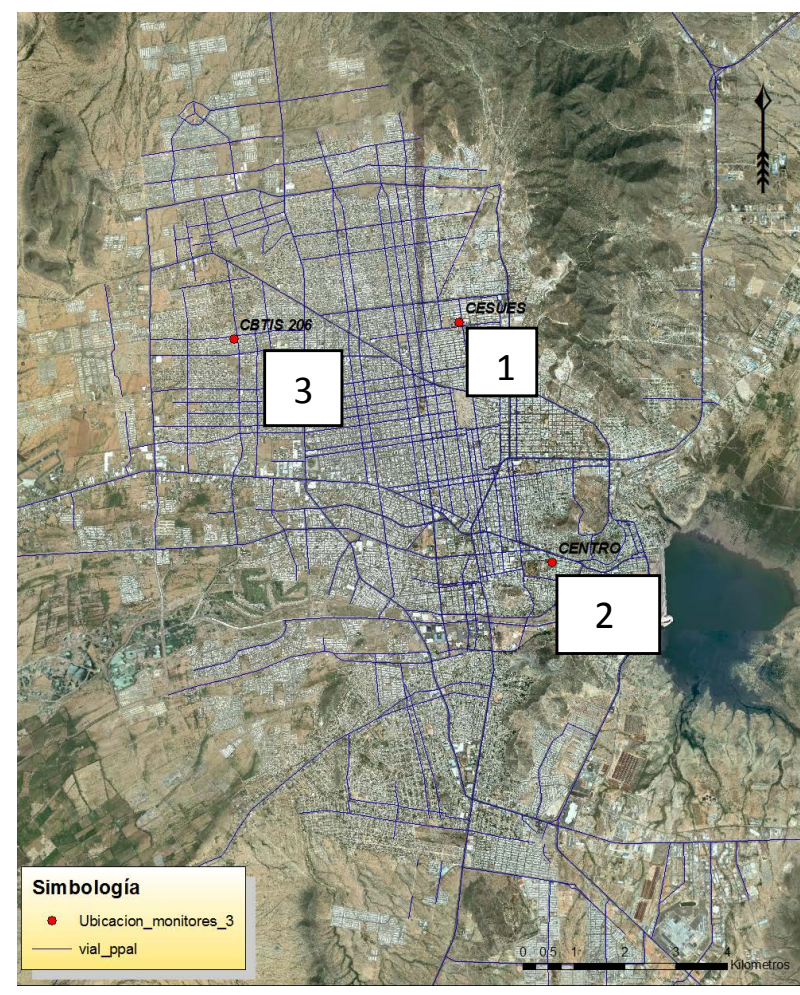

Figure 2. Hermosillo city. Station location.

\subsection{Sampling}

The PM10 particles was collected by high-volume sampler, using a sampling flow of $1.3 \mathrm{~m} / \mathrm{min}$. Sampling was carried for 24-h one day a week. The filters used were quartz, with size of $8 \times 10$ inch that captured PM10 particles.

Analysis of PM10 were performed using electron scanning microscopy (SEM) JEOL Model JSM-5800LV coupled with energy dispersive spectrometer (EDS) EDAX DX prime brand, for determination of morphology and elemental composition of airborne particles. Specimens were processed by separating the collected particles from the quartz filters by means of submersing a $2 \mathrm{~cm}^{2}$ section of each filter into isopropilic alcohol within a test tube for 5 minutes. Then, an aliquot of the suspension was placed over a sample holder, and is introduced into the chamber of SEM.

The images of the samples were taken at a magnification of $500 \times, 1500 \times, 2500 \times, 5000 \times, 7500 \times, 10,000 \times$ and $35,000 \times$. These selected magnifications allow to analyse the chemical and morphological parameters of particles in the entire particle size range considered. Spectra of individual particles were obtained after scanning an electron beam with an accelerating voltage of $15 \mathrm{kV}$ for determination of individual elemental chemical composition of the particles.

Will be identified with EDS spectra the main chemical groups that make up the particles in the study area.

\section{Results and Discussion}

We obtained 150 images of PM10 particles where its morphology and chemical composition of each particle individually was analyzed by SEM-EDS. Figure 3 indicates compositional data of elemental chemical constituents and atomic percentage (At\%) from PM10 particles which showed the following elements: $\mathrm{Al}, \mathrm{Ba}, \mathrm{Ca}, \mathrm{Cl}$, $\mathrm{Cr}, \mathrm{Cu}, \mathrm{Fe}, \mathrm{K}, \mathrm{Mg}, \mathrm{Mn}, \mathrm{Na}, \mathrm{Pb}, \mathrm{S}, \mathrm{Si}$, Ti and U; and the predominant elements were $\mathrm{Al}$ (17.10 At\%), Si (10.17 At\%), Ba (5.90 At\%), Fe (5.45 At\%) and U (2.32 At\%).

In Table 2 images and spectra of individual particles were examined and classified into six groups as particles of alumino-silicate; salts of sodium chloride; sulfates; metal particles; barium and uranium.

The analysis of the data obtained from the images and their respective spectra show that the main characteristics 


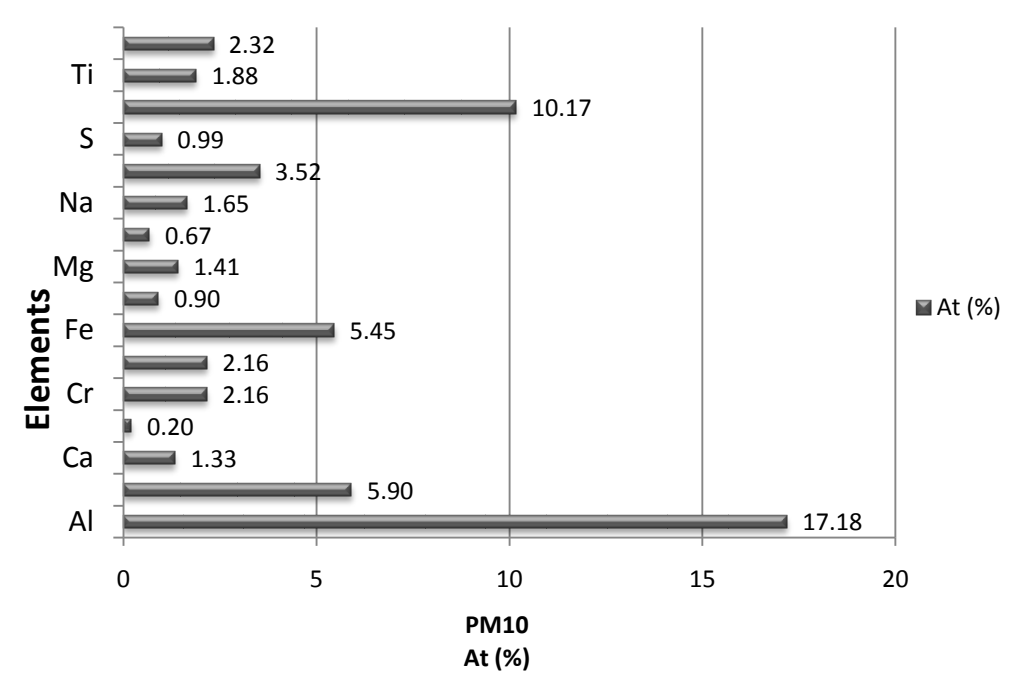

Figure 3. Majority of elemental constituents of PM10 samples in urban area (Averaged values of atomic percentage (At\%) for all filter samples).

Table 2. Classification main SEM-EDS of PM10.

\begin{tabular}{lcc}
\hline \multicolumn{1}{c}{ Groups } & Subgroups & Morphology and texture of particles \\
\hline $\begin{array}{l}\text { 1) Alumino-silicate } \\
\text { 2) } \mathrm{Cl} \text {-Na rich }\end{array}$ & Oxide of silica-aluminium whit trace Na-Ca & Irregular \\
3) Sulfates & Sodium chloride & Crystals tabular \\
4) Metals & Calcium sulfate & Simmetrical, elongated and irregular \\
5) Ba-rich & $\mathrm{Pb}, \mathrm{Cu}, \mathrm{Cr}$ and Fe oxide and sulphate & Irregular and spheroidal \\
6) Uranium & barite $\left(\mathrm{BaSO}_{4}\right)$ & Edges defined \\
\hline
\end{tabular}

and origin of the six groups are:

1) Alumino-silicate: these particles are composed primarily of feldspar ( $\mathrm{Al}, \mathrm{Si}, \mathrm{Ca}$ or $\mathrm{Al}, \mathrm{Si}, \mathrm{K})$ and clay ( $\mathrm{Al}$, $\mathrm{Si}$ or $\mathrm{Al}, \mathrm{Si}, \mathrm{Fe}$ ), their origin is mainly crustal, but they can also come from erosion of building products and road dust. Other elements are present in minor concentration in the alumino-silicate particles and they are $\mathrm{Na}$, Mg, Ti, Mn, Ni and Zn. Within the family of alumino-silicates some crustal particles rich in Si (principally quartz) as described in Figure 4, are included for the similar origin. These particles mainly present an angular shape, ranging from polyhedral to sharp one [2]-[10].

2) Salts of sodium chloride: as seen in Figure 5, these particles consist essentially of $\mathrm{Na}$ and $\mathrm{Cl}$, sometimes traces of $\mathrm{Mg}, \mathrm{K}$, Ca and $\mathrm{S}$ are detected. $\mathrm{NaCl}$ particles are mainly due to marine aerosols. The group of sodium chloride was observed in coarse particles which are originated from sea spray and other natural and anthropogenic activities. Moreover, chloride is also converted into sodium chloride and calcium chloride in the atmosphere which may be due to the secondary particles formation. The shape of these particles is crystals tabular [14].

3) Calcium sulfate: these particles are originated by acid-base neutralization reactions in atmosphere and by deterioration of building's surface, composed of $\mathrm{CaCO}_{3}$ (marble and limestone), and it is due to reaction with sulfur compounds in the atmosphere. Calcium sulfate, described in Figure 6, is also used for the production of cement and it is a secondary product of desulphurisation of flue gas. The shape of these particles is typically simmetrical and elongated, even if there are irregular examples of particles, too [9]-[12].

4) Metal: these are particles with an high metal content such as $\mathrm{Fe}, \mathrm{Zn}, \mathrm{Ti}, \mathrm{Cu}, \mathrm{Mn}, \mathrm{Pb}$ and Cr. Mineral particles with irregular shape were observed in coarse particle which may be mainly derived from natural sources such as soil dust, resuspension of dust from road, crust and some other anthropogenic activities such as construction and vehicles.; particles containing mainly Fe, present in Figure 7, and Pb, for example, can be of crustal 

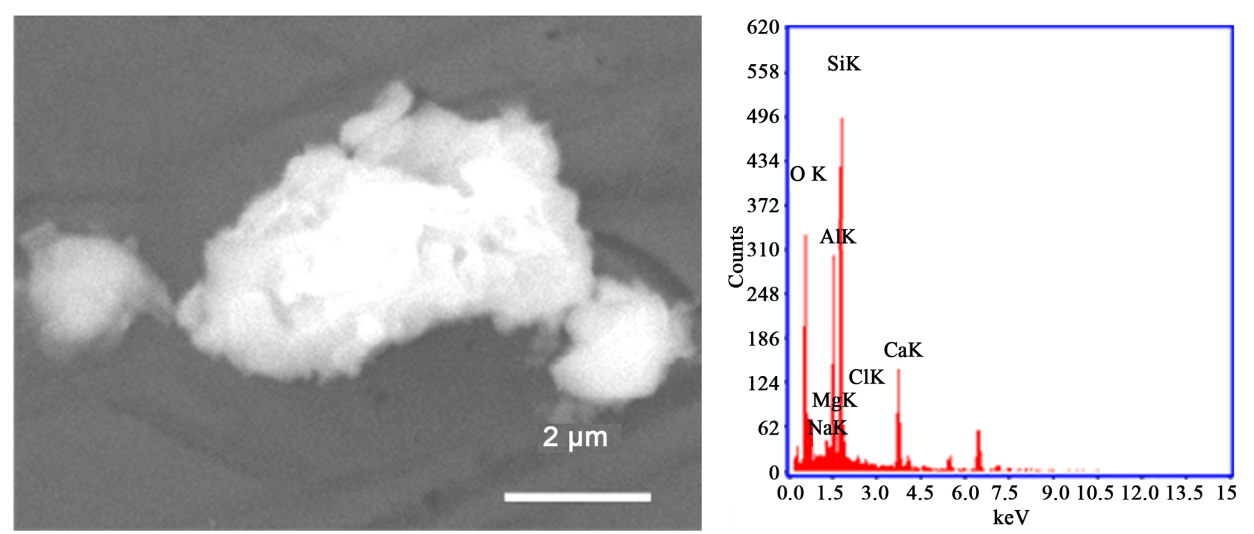

Figure 4. SEM image of quartz particle with characteristic EDS spectra.
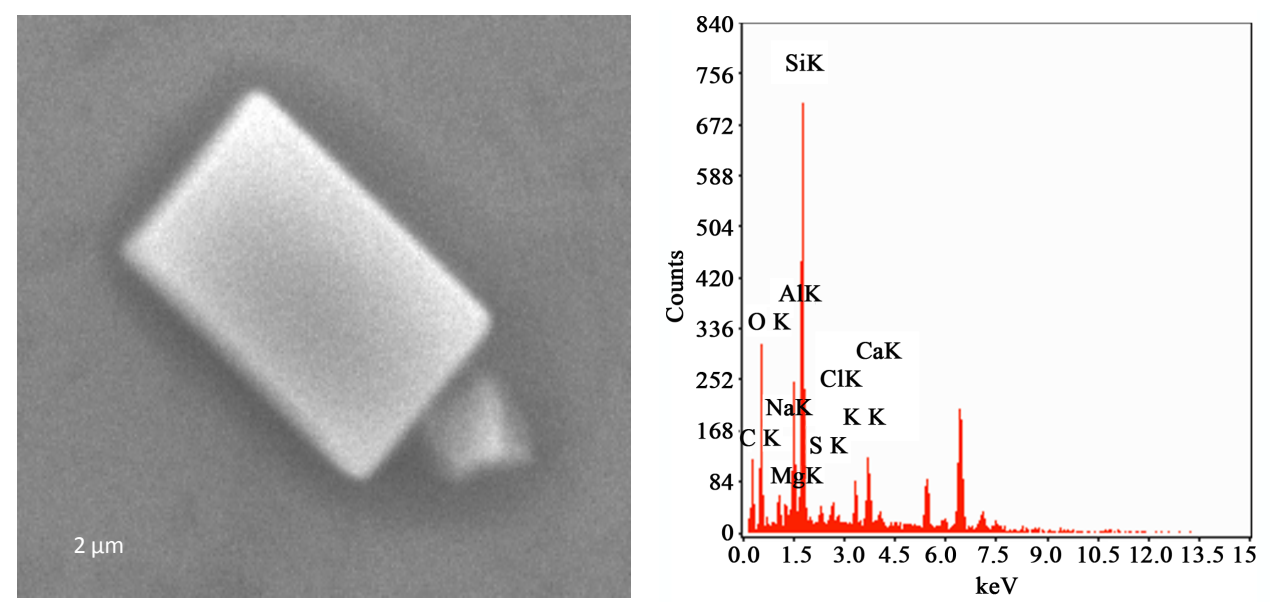

Figure 5. SEM image of sodium chloride particle with characteristic EDS spectra.
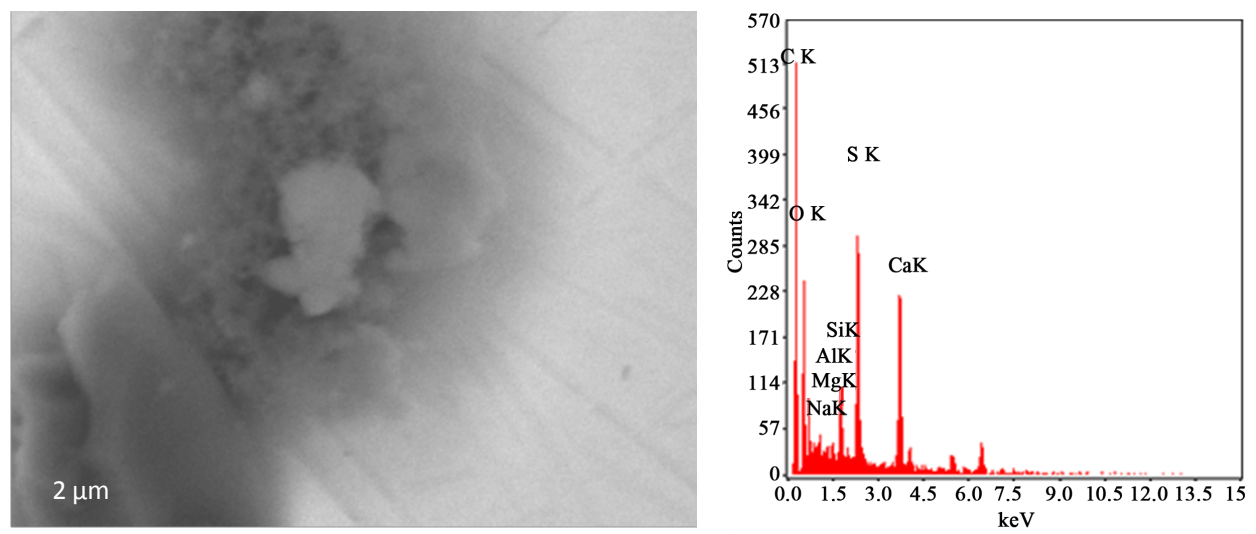

Figure 6. SEM image of calcium sulfate particle with characteristic EDS spectra.

origin, but may also come from human activities such as industrial processes, abrasion of metallic materials and traffic-related sources [15].

5) Barium: its occurrence can be explained partly as result of re-suspension processes, since high concentrations of $\mathrm{Ba}$ are found in soil, primarily as $\mathrm{BaSO} 4$ as described in Figure 8, and partly due to contributions of road surface abrasion, road dust and soil resuspension, brake and tire wear [11].

6) Uranium: is a mixture of three types or isotopes called U-234/234U, U-235/235U and U-238/238U. All three are the same chemical, but they have different radioactive properties. The particles, as seen in Figure 9, 

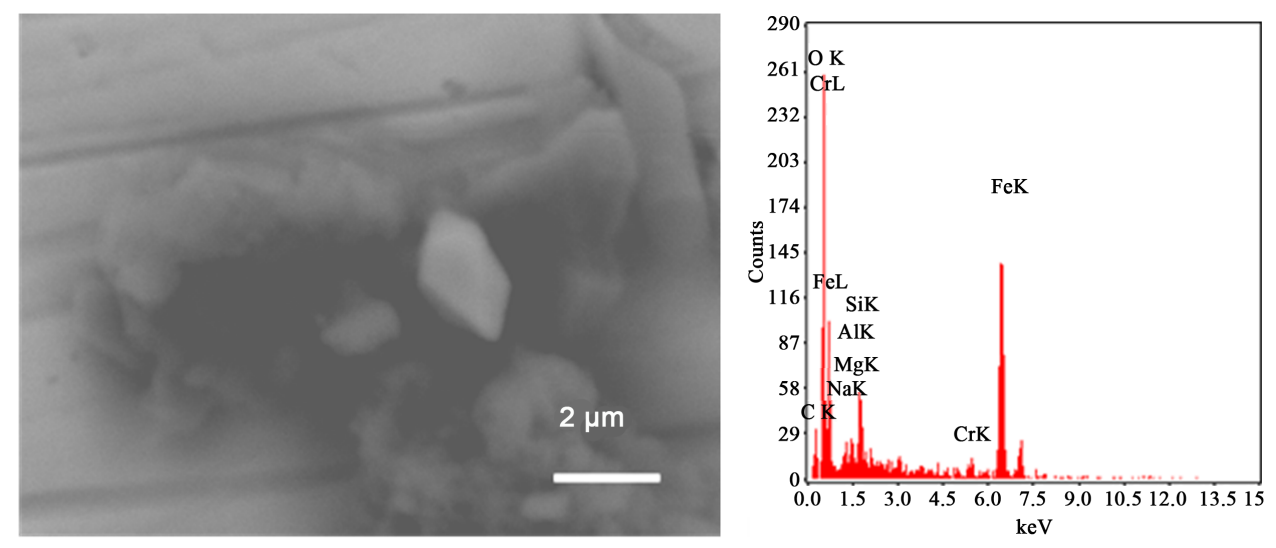

Figure 7. SEM image of iron oxide particle with characteristic EDS spectra.
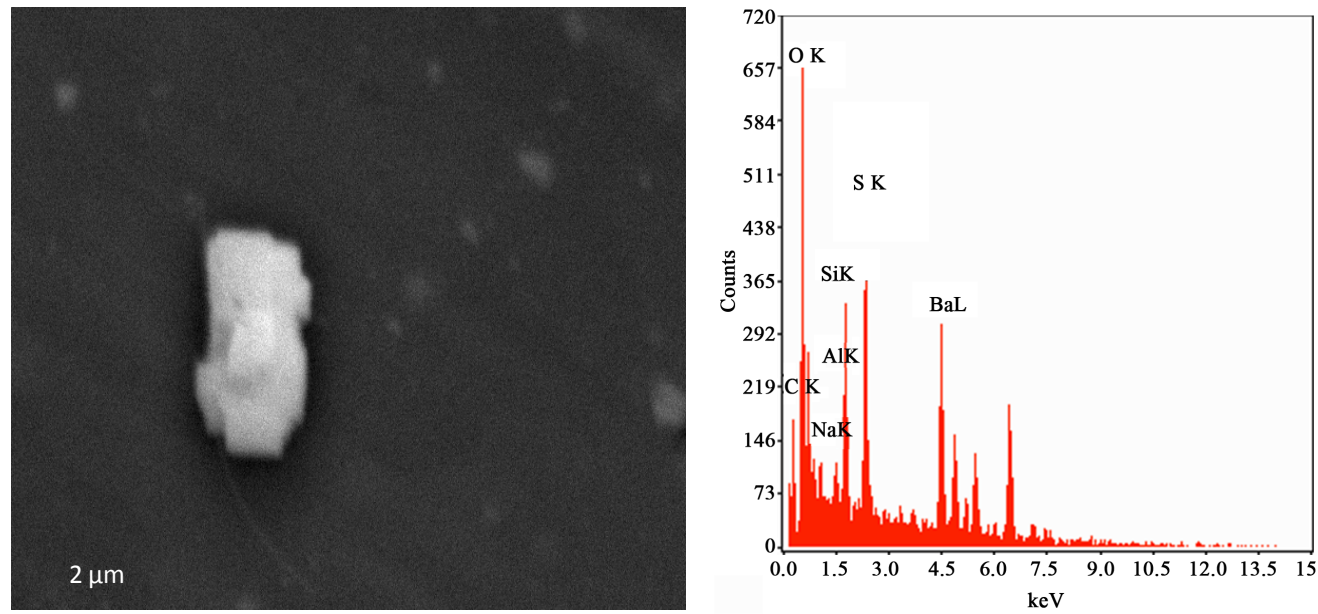

Figure 8. SEM image of barite particle with characteristic EDS spectra.
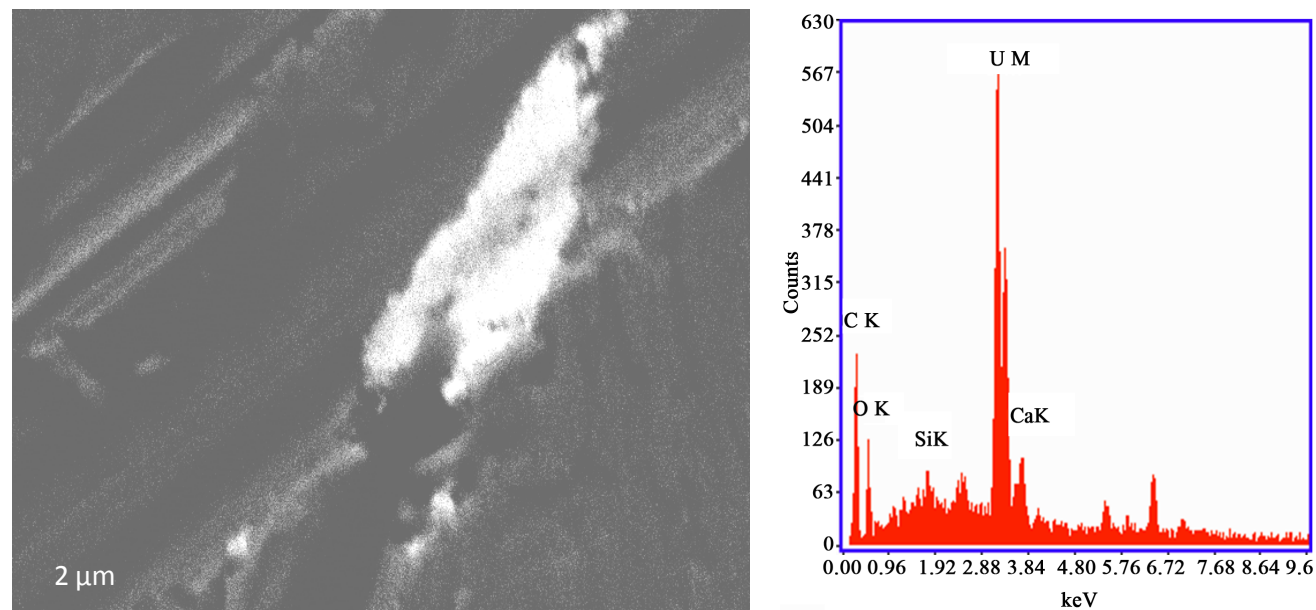

Figure 9. SEM image of uranium particle with characteristic EDS spectra.

have a matrix based on oxides and carbonates of silicon, calcium and uranium; the data indicates that the $U$ is more than likely an intrinsic component of the mineral matrix. The structure of particles can be diverse and they usually present a two dimensional aspect. It is often found that such particles have outlying edges and fracture lines [19]. 


\section{Conclusions}

The chemical analyses performed on the aerosol forming conglomerates allow us to determine air quality on each city. However, these might ignore the chemical elements that occur in smaller amounts because these are not considered or detected during the elaboration of the legislative standards.

The elements found in the filters of PM10 indicate the importance of the individual characterization of atmospheric aerosols, because of the limited amount of information on the speciation and size of atmospheric particles, which allows us to have very valuable additional information on the potential action that these pollutants have. This knowledge is valuable additional information, within air quality program, about the possible actions and potential effects that air pollutants, of natural or anthropogenic origins, may have on the population in the study area.

The SEM-EDS technique is a valuable tool for the characterization of particles of less than $10 \mu \mathrm{m}$ (PM10). Additionally, the identification of the morphology and chemical composition of these particles provides valuable information for the determination of their origin. The results presented show the presence of a wide diversity of particles from natural and anthropogenic origin. The results from SEM-EDS microanalysis determined the main elements of the different particle groups and related them to their origin, whether natural (crustal, marine aerosol) or anthropogenic (agricultural fires, industry, fuel-oil combustion).

\section{References}

[1] Bacci, P., Del Monte, M., Longhetto, A., Piano, A., Prodi, F., Redaelli, P., et al. (1983) Characterization of the Particulate Emission by a Large Oil Fuel Fired Power Plant. Journal of Aerosol Science, 14, 557-572. http://dx.doi.org/10.1016/0021-8502(83)90011-3

[2] Ramirez-Leal, R., Esparza-Ponce, H. and Duarte-Moller, A. (2007) Characterization of Inorganic Atmospheric Particles in Air Quality Program with sem, tem and xas. Revista Mexicana de Fisica, 53, 102-107.

[3] Pope, C.A., Burnett, R.T., Thun, M.J., Calle, E.E., Krewski, D., Ito, K. and Thurston, G.D. (2002) Lung Cancer, Cardiopulmonary Mortality, and Long-Term Exposure to Fine Particulate Air Pollution. The Journal of the American Medical Association, 287, 1132-1141. http://dx.doi.org/10.1001/jama.287.9.1132

[4] Berico, M., Luciani, A. and Formignani, M. (2007) Atmospheric Aerosol in an Urbana Area Measurement of tsp and pm10 Standards and Pulmonary Deposition Assessment. Atmospheric Environment, 31, 3659-3665. http://dx.doi.org/10.1016/S1352-2310(97)00204-5

[5] Dockery, D.W. and Pope, C.A. (1994) Acute Respiratory Effects of Particulate Air Pollution. Annual Review of Public Health, 15, 107-132.

[6] Schwartz, J. (1994) Air Pollution and Daily Mortality: A Review and Meta Analysis. Environmental Research, 64, 36-52. http://dx.doi.org/10.1006/enrs.1994.1005

[7] Richards, R.J., Atkins, J., Marrs, T.C., Brown, R.F.R. and Masek, L.C. (1989) The Biochemical and Pathological Changes Produced by the Intratracheal Instillation of Certain Components of Zinc-Hexachloroethane Smoke. Toxicology, 54, 79-88. http://dx.doi.org/10.1016/0300-483X(89)90080-2

[8] Chung, W., Sharifi, V.N., Swithenbank, J., Ossamor, O. and Nolan, A. (2008) Characterisation of Airborne Particulate Matter in a City Environment. Journal of Modern Applied Science, 2, 17-32.

[9] Okada, K. and Kai, K. (2004) Atmospheric Mineral Particles Collected at Quira in the Taklamakan Desert, China. Atmospheric Environment, 38, 6927-6935. http://dx.doi.org/10.1016/j.atmosenv.2004.03.078

[10] Zhai, Y.B., Fu, Z.M. and Wang, L.F. (2012) Characteristic, Composition, and Sources of TSP Investigated by HRTEM/EDS and ESEM/EDS. Environmental Monitoring and Assessment, 184, 6693-6707. http://dx.doi.org/10.1007/s10661-011-2452-5

[11] Ariola, V., D’Alessandro, A., Lucarelli, F., Marcazzan, G., Mazzei, F., Nava, S., et al. (2006) Elemental Characterisation of PM10, PM2.5 and PM1 in the Town of Genova (Italy). Chemosphere, 62, 226-232. http://dx.doi.org/10.1016/j.chemosphere.2005.05.004

[12] Querol, X., Alastuey, A., Puicercus, J.A., Mantilla, E., Ruiz, C.R., Lopez-Soler, A., Plana, F. and Juan, R. (1998) Seasonal Evolution of Suspended Particles around a Large Coal-Fired Power Station: Chemical Characterization. Atmospheric Environment, 30, 3557-3572. http://dx.doi.org/10.1016/1352-2310(96)00108-2

[13] Brook, R.D., Franklin, B., Cascio, W., Hong, Y., Howard, G., Lipsett, M., et al. (2004) Air Pollution and Cardiovascular Disease: A Statement for Healthcare Professionals from the Expert Panel on Population and Prevention Science of the American Heart Association.

[14] Ramirez-Leal, R., et al. (2009) Elemental Chemical Composition, Size and Morphological Characterization of Indi- 
vidual Atmospheric Particles within an Air Quality Program. Microscopy and Microanalysis, 15, 1300-1301.

[15] Hays, D.M., Fine, M.P., Geron, D.C., Kleeman, J.M. and Gullett, K.B. (2005) Open Burning of Agricultural Biomass: Physical and Chemical Properties of Particle-Phase Emissions. Atmospheric Environment, 39, 6747-6764. http://dx.doi.org/10.1016/j.atmosenv.2005.07.072

[16] Semeniuk, T.A., Wise, M.E., Martin, S.T., Russell, L.M. and Buseck, P.R. (2007) Water Uptake Characteristics of Individual Atmospheric Particles Having Coatings. Atmospheric Environment, 41, 6225-6235. http://dx.doi.org/10.1016/j.atmosenv.2007.04.001

[17] Ramirez-Leal, R., Valle-Martinez, M. and Cruz-Campas, M. (2014) Physico-Chemical Characterization of Total Suspended Particles (TSP) Analysis by SEM-EDS. International Journal of Advanced Research, 2, 815-817.

[18] Goldstein, J.I. (1992) Scanning Electron Microscopy and X-Ray Microanálisis. Springer, New York. http://dx.doi.org/10.1007/978-1-4613-0491-3

[19] Ramirez-Leal, R., Duarte-Tagles, H., Burgos-Hernandezn, M. and Chavez-Toledo, C. (2013) SEM-EDS Identification and Characterization of Radioactive Particles in Samples of PM10. Proceedings of Microscopy and Microanalysis, Cambridge University Press, Danvers, 2002-2003. 
Scientific Research Publishing (SCIRP) is one of the largest Open Access journal publishers. It is currently publishing more than 200 open access, online, peer-reviewed journals covering a wide range of academic disciplines. SCIRP serves the worldwide academic communities and contributes to the progress and application of science with its publication.

Other selected journals from SCIRP are listed as below. Submit your manuscript to us via either submit@scirp.org or Online Submission Portal.
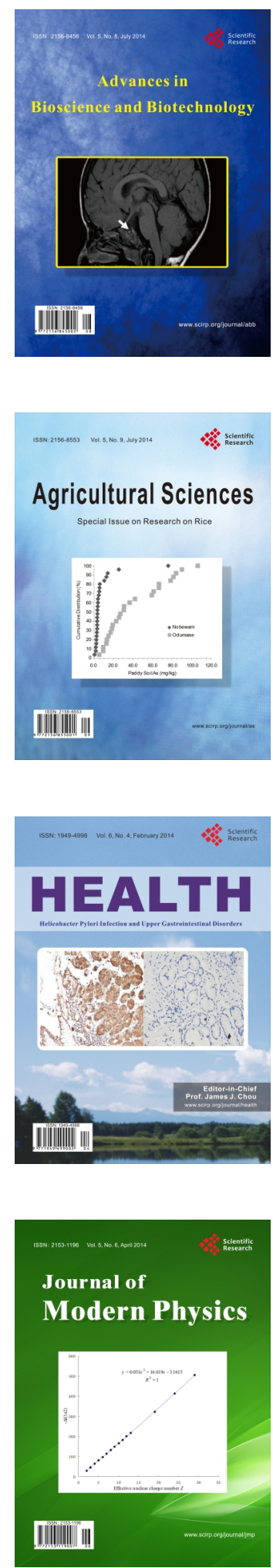
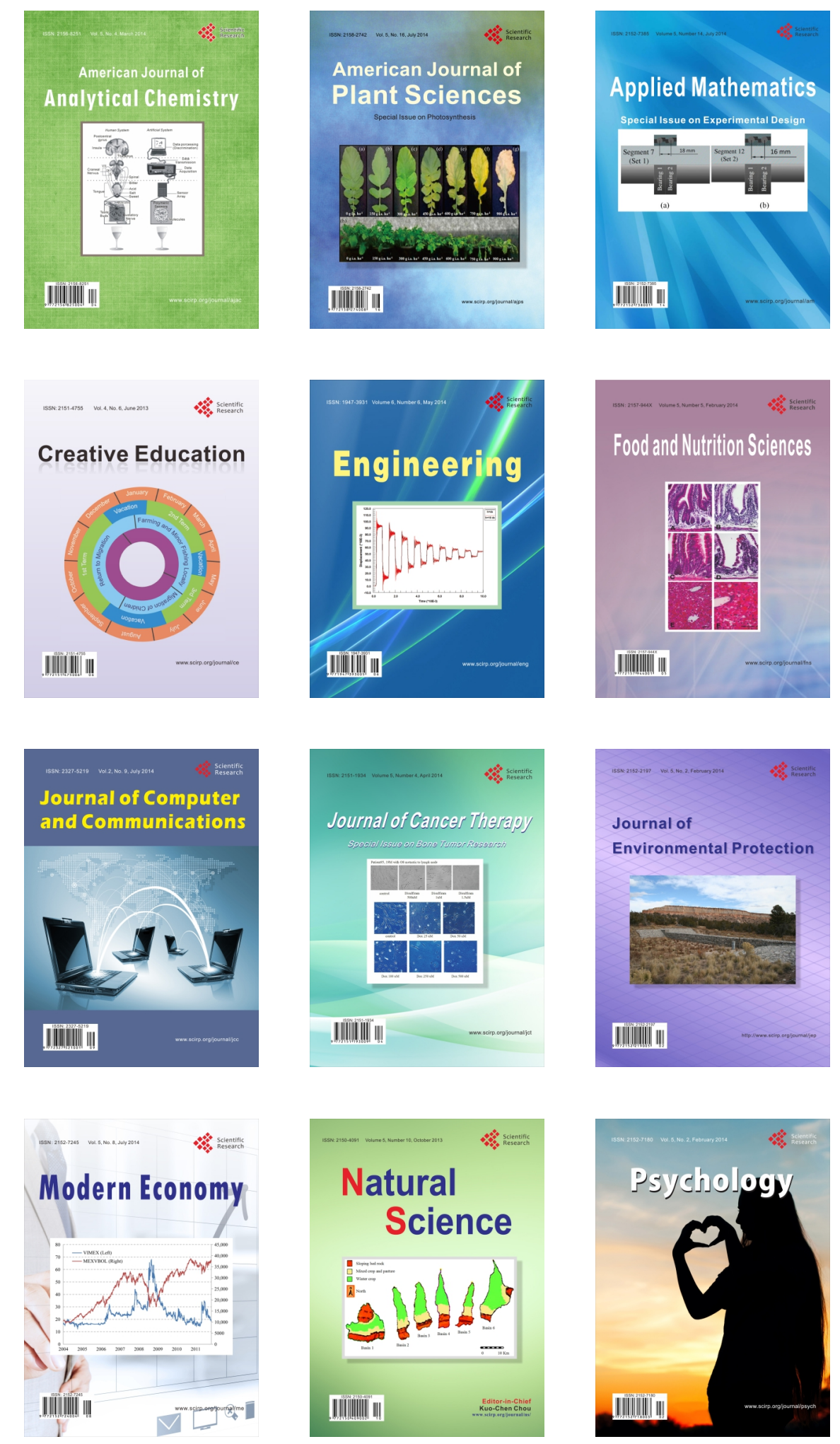